\title{
A Trypsin-Sensitive Proteoglycan from the Tapeworm Hymenolepis diminuta Inhibits Murine Neutrophil Chemotaxis in vitro by Suppressing p38 MAP Kinase Activation
}

\author{
Nicholas Graves ${ }^{a}$ Vivek P. Venu ${ }^{a}$ Bryan G. Yipp ${ }^{b}$ Björn Petric Simon Hirota ${ }^{a}$ \\ John Gilleard ${ }^{d}$ Derek M. McKay ${ }^{a}$ Fernando Lopes ${ }^{a}$ \\ ${ }^{a}$ Gastrointestinal Research Group and Inflammation Research Network, Department of Physiology and \\ Pharmacology, Calvin, Joan and Phoebe Snyder Institute for Chronic Diseases, Cumming School of Medicine, \\ University of Calgary, Calgary, AB, Canada; ${ }^{b}$ Department of Critical Care Medicine, Calvin, Joan and Phoebe Snyder \\ Institute for Chronic Diseases, Cumming School of Medicine, University of Calgary, Calgary, AB, Canada; ${ }^{\mathrm{C}}$ Mouse \\ Phenomics Resource Laboratory, Department of Microbiology, Immunology and Infectious Diseases, Calvin, Joan \\ and Phoebe Snyder Institute for Chronic Diseases, Cumming School of Medicine, University of Calgary, Calgary, \\ $A B$, Canada; dDepartment of Comparative Biology and Experimental Medicine, Faculty of Veterinary Medicine, \\ University of Calgary, Calgary, AB, Canada
}

\section{Keywords}

Chemotaxis · Neutrophils · Parasite-host interactions

\begin{abstract}
It has emerged that neutrophils can play important roles in the host response following infection with helminth parasites. Mice infected with the tapeworm, Hymenolepis diminuta, are protected from some inflammatory conditions, accompanied by reduced neutrophil tissue infiltration. Thus, the ability of a phosphate-buffered saline-soluble extract of the worm $(H$. diminuta extract $[\mathrm{HdE}])$ was tested for $(1)$ its ability to activate murine neutrophils $\left(\mathrm{Ca}^{2+}\right.$ mobilization, reactive oxygen species (ROS) and cytokine production); and (2) affect neutrophil chemotaxis in vitro to the penta-peptide, WKYMVm, the chemokine, $\mathrm{KC}$, and leukotriene $\mathrm{B}_{4}$. $\mathrm{HdE}$ was not cytotoxic to neutrophils, elicited a $\mathrm{Ca}^{2+}$ response
\end{abstract}

\begin{tabular}{ll}
\hline KARGER & ( 2018 The Author(s) \\
Published by S. Karger AG, Basel Openger \\
E-Mail karger@karger.com & This article is licensed under the Creative Commons Attribution- \\
www.karger.com/jin & NonCommercial-NoDerivatives 4.0 International License (CC BY- \\
NC-ND) (http://www.karger.com/Services/OpenAccessLicense). \\
Usage and distribution for commercial purposes as well as any dis- \\
tribution of modified material requires written permission.
\end{tabular}

and ROS, but not, cytokine (KC, interleukin-10, tumour necrosis factor-a) generation. HdE is not a chemotactic stimulus for murine neutrophils. However, a heat- and trypsin-sensitive, acid-insensitive proteoglycan (sensitive to sodium metaperiodate) in the HdE significantly reduced neutrophil chemotaxis towards WKYMVm or KC, but not $\mathrm{LTB}_{4}$. The latter suggested that the HdE interfered with p38 mitogen-activated protein kinase signalling, which is important in WKYMVm chemotaxis. Corroborating this, immunoblotting revealed reduced phosphorylated p38, and the downstream signal heat-shock protein-27, in protein extracts from $\mathrm{HdE}+\mathrm{WkYM}$ Vm treated cells compared to those exposed to the pentapeptide only. We speculate that HdE can be used to modify the outcome of neutrophilic disease and that purification of the bioactive proteoglycan(s) from the extract could be used as a template to design immunomodulatory drugs targeting neutrophils.

(c) 2018 The Author(s)

Published by S. Karger AG, Basel

Dr. Derek M. McKay and Prof. Fernando Lopez

Department of Physiology and Pharmacology, Cumming School of Medicine University of Calgary, 3330 Hospital Drive NW

Calgary, AB T2N 4N1 (Canada)

E-Maildmckay@ucalgary.ca and flopes77@gmail.com 


\section{Introduction}

The neutrophil has traditionally been considered a first-line responder to microbial infections, arriving prearmed with proteases and rapid reactive oxygen species (ROS) generation to kill the invader and with the potential to do considerable collateral damage to host tissue. This is but one of the neutrophils roles, with studies demonstrating important functions in innate immunity and interaction with components of adaptive immunity [1]. Kubes recently detailed the importance of the often-maligned neutrophil in immunity, drawing attention to issues that require clarification such as commonalities and differences in responding to bacterial products versus damaged host tissue, tissue-specific neutrophil activity and the possibility of neutrophil subtypes, among others [1]. With respect to inflammation, recruitment and activation of the neutrophil is often a critical component of acute inflammation; however, in the setting of chronic inflammation, where their capacity to do damage goes unchecked, the neutrophil can contribute to disease. Thus, there can be benefits to promoting neutrophil responses as an immediate reaction to infection and benefits to inhibiting their activity in the setting of chronic inflammatory disease [1].

Based on its classification as an anti-microbial cell, the neutrophil is often overlooked, or dismissed, when considering effector mechanisms mobilized in response to infection with parasitic helminths. This position needs to be re-evaluated. Neutrophils have been implicated in an effective response to the larval stages of the nematodes Lithomosoides sigmodontis, Haemonchus contortus, and Strongyloides steroralis, which can involve myeloperoxidase (MPO) and the release of extracellular traps (i.e., proteases embedded in a chromatin net) [2-5]. Mice infected with Ascaris have increased numbers of neutrophils in their lungs at the peak of helminth migration (and tissue damage) through the airways [6]. Similar findings were presented for Nippostronglyus brasiliensis-infected mice, and suppression of this neutrophil response resulted in reduced mobilization of macrophages capable of killing the parasite and alternatively activated macrophages (AAMs) [7]. In accordance with this, human and mouse neutrophils have been shown to collaborate with macrophages to kill $S$. steroralis larvae in vitro [8]. Finally, in the reciprocal direction of communication, the chitinase-like protein Ym1, that characterizes the murine AAM, has been shown to recruit neutrophils that contributed to the control of $N$. brasiliensis [9].

Tapeworm Suppression of Neutrophil Chemotaxis
A substantial body of evidence illustrates the benefit of infection with helminth parasites in murine models of colitis, diabetes, multiple sclerosis and arthritis [10]. Suppression of inflammatory disease in these model systems can also be achieved by systemic delivery of extracts of the parasites or helminth-derived excretory-secretory products [11]. Using the non-permissive mouse host, we have shown that infection with the rat tapeworm, Hymenolepis diminuta, significantly reduced the severity of dinitrobenzene sulphonic acid-induced colitis (DNBS) [12] and complete Freund's adjuvant (CFA)-induced arthritis [13]. The amelioration of disease in both models was accompanied by lower tissue levels of the neutrophil marker, MPO, and in the case of CFA-induced arthritis, the $H$. diminuta-infected mice had fewer blood neutrophils. The reduced neutrophilia could reflect the impact of host-derived factors (e.g. interleukin [IL]-10), or be mediated by bioactive molecules from the helminth. Consequently, we designed the current study to test the hypothesis that an extract of $H$. diminuta would directly affect neutrophils and their chemotaxis.

\section{Materials and Methods}

\section{Animals}

Male BALB/c mice (6-8 weeks old) were purchased from Charles River Laboratories (Quebec, Canada) and housed under standard conditions with free access to food and water. Animal experiments were conducted with approval from the University of Calgary Health Science Animal Care Committee conforming to national guidelines, under protocol AC13-0015 issued to D.M. McKay.

\section{Preparation of Hymenolepis diminuta Crude Extract}

Adult $H$. diminuta from rats were rinsed in $0.9 \% \mathrm{NaCl}$, and $\sim 20$ g wet weight homogenized in $20 \mathrm{~mL}$ of sterile phosphatebuffered saline (PBS; 5 min, maximum speed, Polytron PT1200 homogenizer [Kinematica, Inc., New York, NY, USA]). The homogenate was centrifuged $\left(3,220 \mathrm{~g}, 30 \mathrm{~min}, 4^{\circ} \mathrm{C}\right)$, pelleted material discarded, the supernatant collected and subjected to 2 additional rounds of centrifugation. The PBS-soluble supernatant was collected, designated $H$. diminuta extract (HdE), the protein concentration determined by the Bradford assay, and aliquots stored at $-80^{\circ} \mathrm{C}$ [14]. Bioactivity of the $\mathrm{HdE}$ was confirmed by its ability to suppress LPS-stimulated production of tumour necrosis factor- $\alpha$ (TNF- $\alpha$ ) by human THP-1 macrophages $\left(2 \times 10^{5}\right.$ PMA [10 nM, 24 h]-activated THP-1 cells were exposed to $\mathrm{HdE}$ [100 $\mu \mathrm{g} / \mathrm{mL}]$ for 30 min and then activated with $10 \mathrm{ng} / \mathrm{mL}$ Escherichia coli-derived LPS. Cell-free conditioned medium was collected $24 \mathrm{~h}$ later and TNF- $\alpha$ measured by enzyme-linked immunosorbent assay [ELISA]) [14]. The HdE preparation contains $<100 \mathrm{pg}$ LPS/1 mg of $\mathrm{HdE}$ protein. The in vivo $(1 \mathrm{mg})$ and in vitro $(100 \mu \mathrm{g})$ doses of $\mathrm{HdE}$ were based on previous studies $[13,14]$ and a dose-response experiment (see Results). 
Assessing the nature of the bioactive molecule in the HdE, the following manipulations were performed: (1) boiled for $15 \mathrm{~min}$; (2) trypsin-treated (1 unit/ $\mu$ g of HdE protein [Sigma-Aldrich] while rocking for $6 \mathrm{~h}$ at room temperature [RT], followed by neutralization with soybean trypsin inhibitor [1 unit inhibitor: 1 unit trypsin; 6 h rocking at $\mathrm{RT}$ )); (3) acidified with $2 \mathrm{~N} \mathrm{HCL}$ to $\mathrm{pH} 2(30$ min at RT followed by normalizing to $\mathrm{pH} 7$ with $2 \mathrm{~N} \mathrm{NaOH}$ ); or, (4) treated with sodium metaperiodate (SMP; Sigma-Aldrich) to disrupt glycans (HdE treated with $10 \mathrm{mM}$ SMP for $30 \mathrm{~min}$ with rocking, following by repeated dialysis [Thermo Fisher] to remove excess SMP) [14]. In all instances, time-matched control HdE was treated identically with the absence of the active reagent.

\section{LPS-Induced Neutrophil Recruitment to Mouse Knee}

After hair removal around the knee, mice received either an intra-articular (ia.) injection of $50 \mathrm{ng}$ E. coli lipopolysaccharide (LPS; $10 \mu \mathrm{L}$ ) (Sigma-Aldrich) or $0.9 \% \mathrm{NaCl}$ (pyrogen free [Baxter Healthcare]) as a control. Some mice were co-treated with HdE ( $1 \mathrm{mg}$, intraperitoneal [ip.] in $1 \mathrm{~mL}$ saline). Six hours after LPS \pm $\mathrm{HdE}$, the knee and peritoneal cavity were washed with PBS and lavages collected, and blood and bone marrow (1 femur) were collected. The total number of leukocytes was determined by counting in a Neubauer chamber after staining with Turk's solution. Differential counts were obtained from cytospin (Shandon III, Thermo Shandon, Frankfurt, Germany) preparations by evaluating the percentage of each class of leukocyte based on nuclear morphology following staining with May-Grünwald-Giemsa [15].

\section{Neutrophil Function in vitro}

Cell Viability

Neutrophil necrosis was assessed via staining with trypan blue $(0.4 \%)$, and measurement of released lactate dehydrogenase using the CytoTox $96^{\circledR}$ kit and following the manufactures instructions (Promega).

\section{Calcium Mobilization}

Mice were humanely euthanized, bone-marrow extracted from the femurs and tibias under sterile conditions and neutrophils isolated via a differential Percoll gradient following the protocol of Swamydas et al. [16] Neutrophils $\left(2.5 \times 10^{6}\right.$ cells $\left./ \mathrm{mL}\right)$ were incubated with the intracellular $\mathrm{Ca}^{2+}$ indicator dye Fluo-4 $(2.5 \mu \mathrm{M}$, Sigma-Aldrich) for $45 \mathrm{~min}$ at RT while gently shaking, then centrifuged at $300 \mathrm{~g}$ for $10 \mathrm{~min}$. The supernatant was discarded and the cells re-suspended in Hank's balanced salt solution $\pm \mathrm{Ca}^{2+}$. Aliquots of $10^{5}$ cells $(100 \mu \mathrm{L})$ in $1 \mathrm{~mL}$ cuvettes were placed in a fluorescence spectrophotometer (Cole-Parmer, Montreal, Canada) and treated with $\mathrm{HdE}(100 \mu \mathrm{g} / \mathrm{mL})$, the pentapeptide WKYMVm (1.0 $\mu \mathrm{M}$, Tocris Bioscience), calcium ionophore, A23187 (2.5 $\mu \mathrm{M}$, Sigma-Aldrich) or zymosan ( $1 \mu \mathrm{g} / \mathrm{mL}$, Sigma Aldrich), as positive controls. Cells were excited at $480 \mathrm{nM}$ and fluorescence measured at $530 \mathrm{nM}$, and recorded as the peak increase to occur within $3 \mathrm{~min}$ of treatment.

\section{Mitochondrial Respiration}

Neutrophil bioenergetics was determined using the Seahorse Bioscience extracellular flux analyzer (Agilent, Santa Clara, CA, USA), which measures $\mathrm{O}_{2}$ consumption and proton flux. Overnight hydrated $\mathrm{XF}^{\mathrm{e}} 24$ probes in calibrant solution were loaded with oligomycin $(0.5 \mu \mathrm{g} / \mathrm{mL}$; inhibits ATP synthase), carbonyl cyanide-4-(trifluoromethoxy)phenylhydrazone (FCCP, $0.6 \mu \mathrm{g} / \mathrm{mL}$;
$\mathrm{H}^{+}$ionophore uncoupling oxidative phosphorylation) and antimycin $(10 \mu \mathrm{M}$; binds to the Qi site of cytochrome c reductase (compel III in electron transport chain)) in ports $\mathrm{B}, \mathrm{C}$ and $\mathrm{D}$ respectively. Port A was filled with $\mathrm{HdE}(100 \mu \mathrm{g} / \mathrm{mL})$. Experimental media was used as control. Neutrophils were plated on $\mathrm{XF}^{\mathrm{e}} 24$ plates. The cartridge and cells were equilibrated in a $37^{\circ} \mathrm{C}$, non- $\mathrm{CO}_{2}$ incubator for $1 \mathrm{~h}$ prior to assay. The oxygen consumption rate was monitored continuously and proton leak and ATP levels determined following the manufacturer's instructions and as described by Dranka et al. [17], with slight modification. We replaced the mixing step with longer incubation to avoid neutrophil aggregation. The results were plotted using Wave software from Agilent.

\section{Reactive Oxygen Species Generation}

Neutrophils $\left(10^{8}\right.$ cells $\left./ \mathrm{mL}\right)$ were re-suspended in $20 \mu \mathrm{M} 2^{\prime}, 7^{\prime}$-dichlorofluorescin diacetate (Abcam, Eugene, OR, USA), a fluorogenic dye that measures hydroxyl, peroxyl and other ROS, for 30 min at $37^{\circ} \mathrm{C}[18]$. Then $10^{5}$ cells $/ 100 \mu \mathrm{L}$ were added to each well of a dark, clear-bottom 96 well plate (Thermo Fisher) and treated with HdE $(100 \mu \mathrm{g} / \mathrm{mL})$, E. coli-derived LPS $(1 \mu \mathrm{g} / \mathrm{mL}$; Sigma-Aldrich) or both agents. In addition, some wells received polymyxin $\mathrm{B}(10 \mu \mathrm{g} / \mathrm{mL}$; Sigma-Aldrich) to neutralize LPS. Plates were incubated at $37^{\circ} \mathrm{C}$ for $4 \mathrm{~h}$ and fluorescence read in a Victor- 5 multilabel plate reader (excitation $535 \mathrm{~nm}$, emission $485 \mathrm{~nm}$ ) (Perkin Elmer).

\section{Enzyme-Linked Immunosorbent Assay}

Neutrophils $\left(10^{5} / \mathrm{mL}\right)$ were exposed to HdE $(100 \mu \mathrm{g} / \mathrm{mL}), E$. coli-derived LPS $(1 \mu \mathrm{g} / \mathrm{mL})$ or E. coli (strain HD5- $\alpha$; $10^{6}$ colonyforming units [America Type Culture Collection]). Four h later, supernatants were collected and levels of TNF- $\alpha$, IL-10, and KC measured in duplicate samples by ELISA with DuoSet ${ }^{\circledR}$ kits from R\&D Systems (Minneapolis, MN, USA), and following the manufacturer's instructions.

In other experiments, PBS or $\mathrm{HdE}(100 \mu \mathrm{g}$ in $100 \mu \mathrm{L})$ was injected into the peritoneal cavity of mice and $6 \mathrm{~h}$ later the cavity washed with $\mathrm{PBS}$, a $1 \mathrm{~mL}$ lavage retrieved and $\mathrm{KC}$ levels determined by ELISA.

\section{Neutrophil Chemotaxis}

Under Agarose Gel Assay

An ultrapure agarose gel was prepared as previously described [19] and $3 \mathrm{~mL}$ aliquots were added to plasma-treated $35 \mathrm{~mm}$ diameter Petri culture dishes (Waltham), which were left to harden for $45 \mathrm{~min}$ at RT, at which time a centre well and one to the right and left of centre were cut. The chemoattractant, WKYMVm $(1 \mu \mathrm{M})$ or $\mathrm{HdE}(100-1,000 \mu \mathrm{g} / \mathrm{mL})$ was added into the centre well and neutrophils $\left(10^{4}\right)$ placed in the outer wells. In other experiments, neutrophils were treated with $\operatorname{HdE}(100 \mu \mathrm{g} / \mathrm{mL})$ for $30 \mathrm{~min}$, then rinsed prior to use in the chemotaxis assay. The number of neutrophils that moved into the space between neutrophil and WKYMVm chambers at the end of a $4 \mathrm{~h}$ incubation at $37^{\circ} \mathrm{C}$ was counted (duplicate neutrophil samples were used from each mouse and the average number of migrating neutrophils determined).

\section{Transwell Assay}

Chemoattractants (WKYMVm [2 $\mu \mathrm{M}$ ], KC [keratinocyte-derived chemokine, or CXCL1 or GROa; $20 \mathrm{nM}$ ] and leukotriene $\mathrm{B}_{4}$ $\left[\mathrm{LTB}_{4}, 100 \mathrm{nM}\right]$ ) were diluted in serum-free RPMI culture medium and added to the basal chamber of 24-well culture plates that con- 
tained $8-\mu \mathrm{m}$ porous filter supports (Fisher, Scientific). Neutrophils $\left(2 \times 10^{5}\right)$ were placed in the upper compartment of the transwell, the plate placed at $37^{\circ} \mathrm{C}$ for $4 \mathrm{~h}$ and subsequently neutrophils that had migrated into the basal chamber were retrieved and counted on a hemocytometer [20]. Neutrophils were either pre-treated with $\mathrm{HdE}(100 \mu \mathrm{g} / \mathrm{mL})$ for $30 \mathrm{~min}$ prior to use or HdE was added to the apical chamber of the transwell coincident with the application of the neutrophils (duplicate neutrophil samples were assessed from each mouse).

In separate experiments, the pan-caspase inhibitor, Z-VAD (20 $\mu \mathrm{M})$, LPS $(1 \mu \mathrm{g} / \mathrm{mL}), \mathrm{A} 23187(2.5 \mu \mathrm{M})$, the general antioxidant, $\mathrm{n}$ acetylcystine (NAC, $1 \mu \mathrm{M}$ ) or the mitochondria-targeted antioxidant, MitoTEMPO (10 $\mu \mathrm{M}$, Sigma-Aldrich) were used to assess roles for apoptosis, activation and ROS in the HdE-elicited suppression of neutrophil chemotaxis respectively.

\section{Protein Detection on Immunoblotting}

Protein samples from neutrophil whole-cell extracts were assessed using a standard immunoblotting protocol, with the following antibodies: rabbit polyclonal phospho-p38 primary antibody (1:1,000, Cell Signalling, ${ }^{\# 9211) ; ~ r a b b i t ~ p o l y c l o n a l ~} \beta$-actin antibody (1:1,000, Abcam, $\left.{ }^{\#} 8227\right)$; rabbit polyclonal phospho-heatshock protein (HSP)27 (1:1,000, Cell Signaling, $\left.{ }^{\#} 2401\right)$.

\section{Statistics and Data Presentation}

Data comprised of mean \pm SD. Data sets with $n \geq 5$ were subjected to the Brown-Forsythe test for normal distribution and were analyzed by parametric one-way analysis of variance with Tukey's post-test for multiple group comparison or non-parametric Kruskal-Wallis test with Dunn's post-test or Student $t$ test for two data sets using Graph Prism 6 statistical package. $p<0.05$ was accepted as a level of statistically significant difference.

\section{Results}

\section{HdE Attenuates LPS-Induced Neutrophil Recruitment} to the Knee

Lavage of knees showed that LPS induced robust recruitment of immune cells into the cavity by $6 \mathrm{~h}$ posttreatment, with differential cell counts revealing that the increase in leucocytes was almost entirely due to neutrophils: co-treating animals with HdE attenuated this neutrophil recruitment (Fig. 1a). Analysis revealed that HdE resulted in significant accumulation of neutrophils in the peritoneal cavity (Fig. 1b). As a percentage of total cells in the peritoneum, neutrophils were control $=1 \pm 0.3 \%$, LPS (ia.) $=3 \pm 1.2 \%$, and LPS (ia.) + HdE (ip.) $=76 \pm 4 \%$. The neutrophil recruitment in response to injection of $\mathrm{HdE}$ could be due, in part, to evoked production of $\mathrm{KC}$ by resident cells in the peritoneum (PBS treated mice $=168 \pm$ 113 compared to HdE [100 $\mu \mathrm{g}, 6 \mathrm{~h}]$ treated mice $=1,891 \pm$ $200 * \mathrm{KC}$ pg/mL [mean $\left.\pm \mathrm{SEM}, n=3,{ }^{*} p<0.05\right]$ ). However, neither the numbers nor percentages of neutrophils in the blood and bone marrow were different between the experimental groups (Fig. 1c, d), suggesting that the HdEevoked reduction in neutrophils into the knee following injection of LPS was not simply due to diversion of the cells to the peritoneal cavity.

\section{HdE Is Not Cytotoxic on Murine Neutrophils}

Giemsa staining and nuclear morphology analysis revealed that the population of cells isolated from bone marrow was $88-94 \%$ neutrophils $(n=4)$. Neutrophils tend not to survive well in vitro (hence the 4 -h time-point in the following experiments); however, we observed no additional cytotoxic effects of $\mathrm{HdE}$ on murine bone marrow-derived neutrophils as gauged by exclusion of the vital dye, trypan blue, or lactate dehydrogenase release (Table 1).

\section{HdE Activates Murine Neutrophils}

Calcium mobilization was chosen as a general indicator of cell responsiveness, with A23187- and zymosantreated neutrophils displaying a robust response; WYKMVm evoked a response of lesser magnitude (Fig. 2a, b). Preliminary observations revealed that the addition of HdE alone to the cuvette (no neutrophils) gave an increase in signal in the spectrophotometer most likely due turbidity of the solution, and so the neutrophil response to $\mathrm{HdE}$ is the gradual increase in signal after the initial spike; a very different $\mathrm{Ca}^{2+}$ mobilization event as compared to A23187 or zymosan (Fig. 2a). HdE also evoked a $\mathrm{Ca}^{2+}$ response when experiments were conducted in $\mathrm{Ca}^{2+}$-free medium, suggesting the capacity to mobilize $\mathrm{Ca}^{2+}$ from intracellular stores (Fig. 2c).

Calcium mobilization is important in ROS generation and HdE $(100 \mu \mathrm{g} / \mathrm{mL})$ was as effective as LPS $(1 \mu \mathrm{g} / \mathrm{mL})$ in evoking ROS in neutrophils: treatment with both agents induced a significantly greater respiratory burst than either agent alone (Fig. 3). Assessing the potential confounding factor of LPS contamination in HdE, the worm extract was treated with polymyxin B (neutralizes LPS $^{8}$ ). Polymyxin B treatment did not inhibit HdE-induced ROS production but did inhibit the ability of LPS to induce ROS (Fig. 3).

Analysis of mitochondrial respiration revealed that neutrophils treated with HdE where compromised in their response to oligomycin, and the perturbation of the ATP synthase resulted in decreased ATP production and a corresponding increase in proton leak across the mitochondrial inner membrane (Fig. 3b).

In contrast to ROS production, a $4 \mathrm{~h}$ exposure to $\mathrm{HdE}$ did not evoke any significant increases in TNF- $\alpha, \mathrm{KC}$ or IL-10 from neutrophils (Table 2). The inability of HdE to 

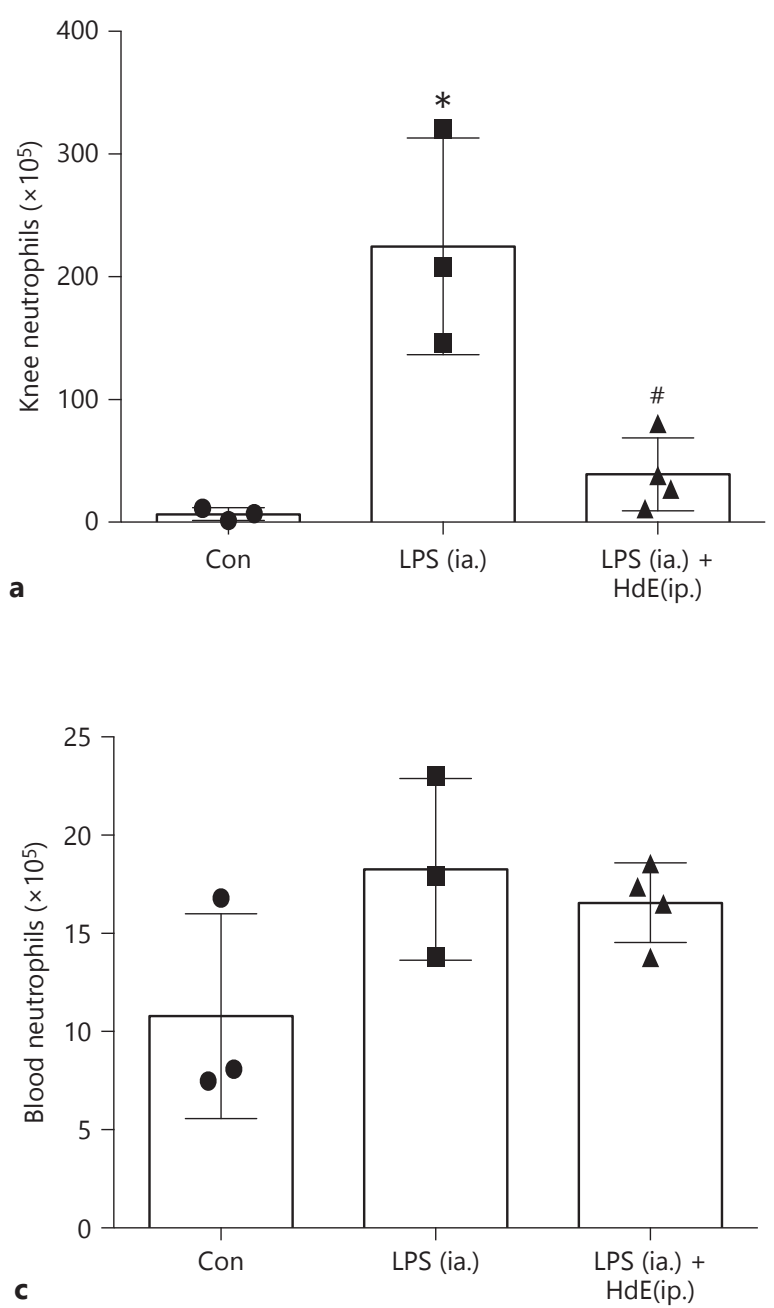

Fig. 1. H. diminuta extract (HdE) attenuates LPS-induced neutrophil recruitment to the knee. Lipopolysaccharide (LPS, $50 \mathrm{ng} / 10$ $\mu \mathrm{L}$ ) or sterile phosphate-buffered saline (PBS) were injected into the knee cavity (intra-articular [ia.]) \pm co-treatment with HdE (1 $\mathrm{mg} / 1 \mathrm{~mL}$ intraperitoneal [ip.]) or vehicle. Six hours later the knee cavity was washed to collect cells (a; representative of 3 experiments). Cells were also collected from the peritoneal cavity by
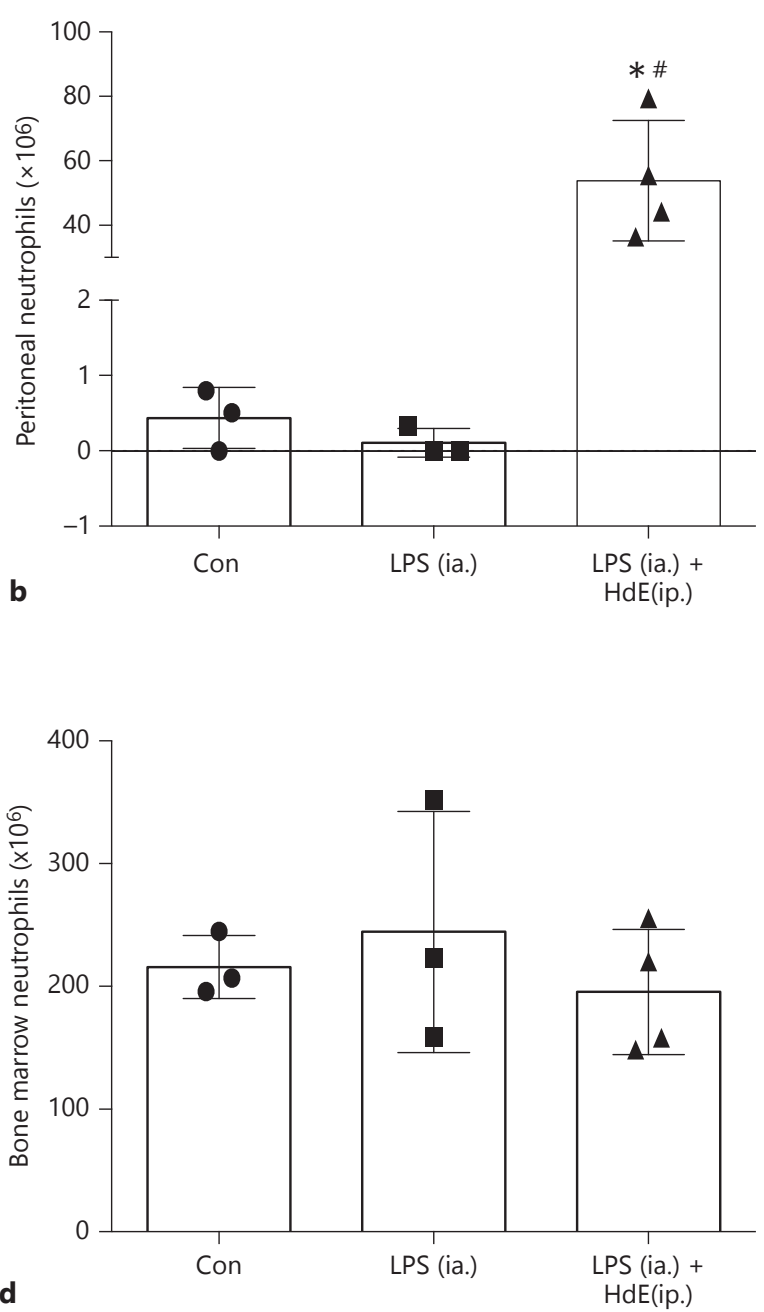

Table 1. HdE is not preferentially cytotoxic to murine bone marrow-derived neutrophils over a 16-h period

\begin{tabular}{|c|c|c|c|c|c|c|c|c|c|c|c|}
\hline & \multirow{2}{*}{\multicolumn{2}{|c|}{ Control }} & \multicolumn{6}{|c|}{$\mathrm{HdE}, \mu \mathrm{g} / \mathrm{mL}$} & \multirow{2}{*}{\multicolumn{2}{|c|}{$\begin{array}{l}\text { Staurosporine } \\
1 \mu \mathrm{M}\end{array}$}} & \multirow{3}{*}{$\begin{array}{l}\text { Distilled } \\
\mathrm{H}_{2} \mathrm{O} \\
4 \mathrm{~h}\end{array}$} \\
\hline & & & \multicolumn{2}{|l|}{100} & \multicolumn{2}{|l|}{500} & \multicolumn{2}{|l|}{1,000} & & & \\
\hline & $4 \mathrm{~h}$ & $16 \mathrm{~h}$ & $4 \mathrm{~h}$ & $16 \mathrm{~h}$ & $4 \mathrm{~h}$ & $16 \mathrm{~h}$ & $4 \mathrm{~h}$ & $16 \mathrm{~h}$ & $4 \mathrm{~h}$ & $16 \mathrm{~h}$ & \\
\hline $\begin{array}{l}\text { \% viable } \\
\mathrm{LDH}\left(\mathrm{AU} \times 10^{5}\right)\end{array}$ & $\begin{array}{c}92 \pm 2 \\
3.0 \pm 0.8\end{array}$ & $\begin{array}{l}47 \pm 4 \\
\mathrm{nt}\end{array}$ & $\begin{array}{c}90 \pm 4 \\
3.4 \pm 0.9\end{array}$ & $\begin{array}{l}45 \pm 9 \\
\mathrm{nt}\end{array}$ & $\begin{array}{c}90 \pm 4 \\
3.5 \pm 0.7\end{array}$ & $\begin{array}{l}43 \pm 4 \\
\mathrm{nt}\end{array}$ & $\begin{array}{l}90 \pm 5 \\
2.7 \pm 0.7\end{array}$ & $\begin{array}{l}45 \pm 6 \\
\mathrm{nt}\end{array}$ & $\begin{array}{l}88 \pm 4 \\
\mathrm{nt}\end{array}$ & $\begin{array}{l}10 \pm 5 \\
\mathrm{nt}\end{array}$ & $\begin{array}{l}\text { nt } \\
5.1 \pm 1.0\end{array}$ \\
\hline
\end{tabular}

Data is mean $\pm \mathrm{SD}, n=4$ mice for trypan blue \% viability and $n=6$ mice for lactate dehydrogenase (LDH); AU, arbitrary units; nt, not tested; h, hour; duplicate samples of neutrophils/mouse; HdE, Hymenolepis diminuta extract. 


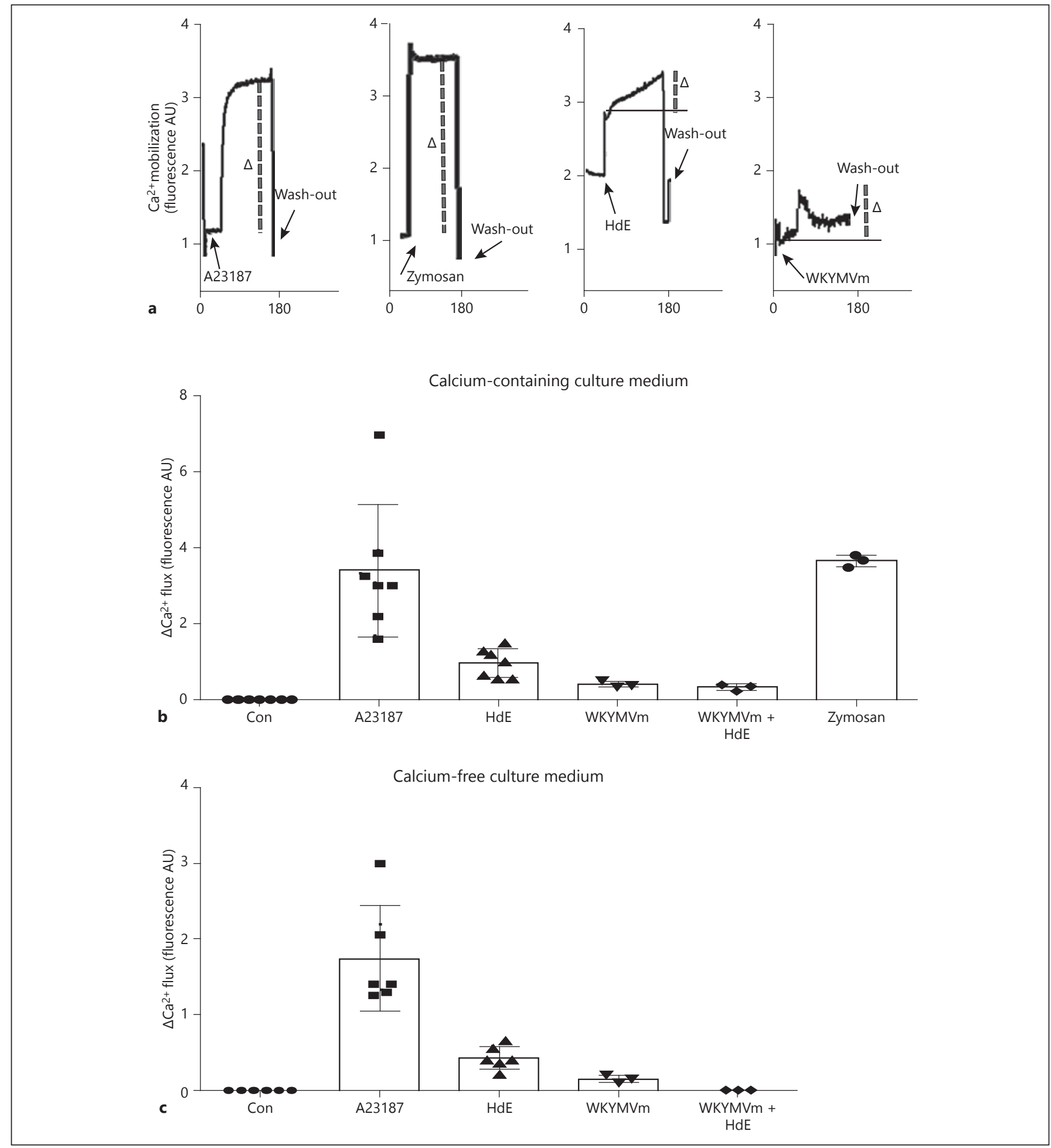

Fig. 2. $H$. diminuta extract $(\mathrm{HdE})$ mobilizes calcium in murine bone marrow neutrophils. Neutrophils $\left(10^{5}\right)$ were loaded with Furo- $4(2.5 \mu \mathrm{M})$ and then challenged with the calcium ionophore, A231877 $(2.5 \mu \mathrm{M})$, zymosan $(1 \mu \mathrm{g} / \mathrm{mL}), \mathrm{HdE}(100 \mu \mathrm{g} / \mathrm{mL})$ or the peptide WKYMVm $(1 \mu \mathrm{M})$ and the maximum increase in fluorescence measured in arbitrary units (AU) that occurred within $3 \mathrm{~min}$ was recorded. a Representative tracings from the spectrophotometer. $\mathbf{b}$ and $\mathbf{c}$ show the peak responses (see $\Delta$ and dashed line on $\mathbf{a}$ ) recorded in $\mathrm{Ca}^{2+}$-containing and $\mathrm{Ca}^{2+}$-free medium, respectively (data are mean $\pm S D$; each datum is the average of 2 neutrophil replicates from an individual mouse). 
Fig. 3. H. diminuta extract (HdE) elicits a reactive oxygen species (ROS) response from murine bone-marrow neutrophils. a Neutrophils $\left(10^{5}\right)$ were treated with the ROS detector 2',7'-dichlorofluorescin diacetate (DCFDA; $20 \mu \mathrm{M})$, then challenged with E. coli-derived lipopolysaccharide (LPS; $1 \mu \mathrm{g} / \mathrm{mL})$ or HdE $(100 \mu \mathrm{g} / \mathrm{mL}) \pm$ polymyxin B (PmxB; $10 \mu \mathrm{g} / \mathrm{mL})$ to neutralize LPS. Four hours later, ROS generation was measured as the increase in fluorescence and is presented as arbitrary units (AU). b Reduction in mitochondrial respiration induced by $\mathrm{HdE}$ as gauged by oxygen consumption rates (OCR), proton leak and ATP production analyzed by the Seahorse assay (data are mean $\pm \mathrm{SD}$; each datum point is the average of 2 neutrophil replicates from an individual mouse; ${ }^{*}$ and \# $p<0.05$ compared to control [con] and LPS, respectively, by one-way analysis of variance with Tukey's post-test).
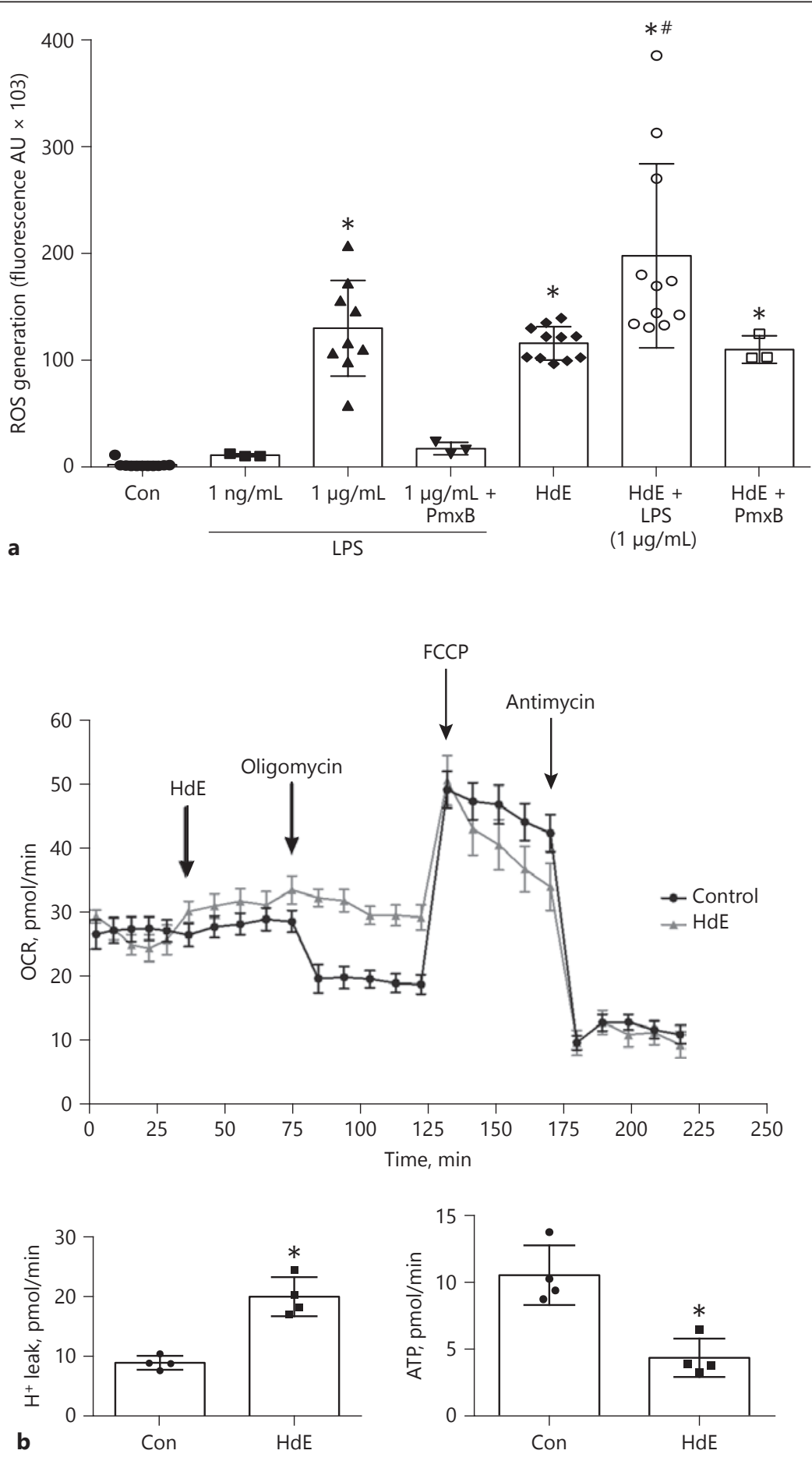

affect the output of these cytokines does not dismiss the possibility that the worm extract could affect neutrophil synthesis and release of other cytokines, lipid-mediators or enzymes, such as elastase. This possibility should be considered in additional studies.
HdE Is Not Directly Chemotactic for Neutrophils but Blocks Responses to WKYMVm and KC, but Not LTB 4 Employing the under-agarose assay, neutrophil migration in response to WKYMVm was obvious but did not occur in response to HdE (100-1,000 $\mu \mathrm{g} / \mathrm{mL}$; Fig. 4a). More- 
Table 2. HdE does not evoke a murine neutrophil cytokine response

\begin{tabular}{lllllll}
\hline & Control & HdE & LPS & LPS and HdE & E. coli & E. coli and HdE \\
\hline KC & $44 \pm 5$ & $3 \pm 4$ & $338 \pm 119^{*}$ & $450 \pm 188^{*}$ & nt & nt \\
IL-10 & $33 \pm 9$ & $20 \pm 12$ & nt & nt & $392 \pm 85^{*}$ & $447 \pm 50^{*}$ \\
TNF- $\alpha$ & $36 \pm 31$ & $68 \pm 32$ & $701 \pm 456^{*}$ & $499 \pm 117^{*}$ & nt & nt \\
\hline
\end{tabular}

Data is $\mathrm{pg} / \mathrm{mL}$ mean $\pm \mathrm{SD}$ measured $4 \mathrm{~h}$ after treatment; $n=6 ; \mathrm{HdE}$ at $100 \mu \mathrm{g} / \mathrm{mL} ; \mathrm{LPS}$ at $1 \mu \mathrm{g} / \mathrm{mL} ;$ E. coli strain DH5- $\alpha$ at $10^{6}$ colony forming units; nt, not tested; ${ }^{*} p<0.05$ compared to control.

HdE, Hymenolepis diminuta extract; IL, interleukin; TNF- $\alpha$, tumor necrosis factor- $\alpha$.

over, when neutrophils were pre-treated with $\mathrm{HdE}(100 \mu \mathrm{g} /$ $\mathrm{mL}, 37^{\circ} \mathrm{C}, 30 \mathrm{~min}$ ) they showed significantly reduced chemotaxis to WKYMVm (Fig. 4b). Reduced chemotaxis to WKYMVm by HdE-treated neutrophils was also observed in the transwell migration assay (Fig. 4c), as was chemotaxis to KC (Fig. 4d). Neutrophil chemotaxis towards $\mathrm{LTB}_{4}$ was unaffected by HdE pre-treatment (Fig. 4e).

Neutrophils co-treated with HdE at the time of addition of WKYMVm to the basolateral chamber of the culture transwell displayed reduced chemotaxis (Fig. 4f). The reduced chemotaxis of HdE-treated neutrophils was not due to apoptosis, a generalized activation event causing stasis, or ROS, as determined by the use Z-VAD, LPS, A23187, NAC or MitoTEMPO, respectively (Fig. 5). With $\mathrm{HdE}$ being effective in a pre-treatment regimen ( $\mathrm{HdE}$ rinsed from neutrophils prior to use) in the WKYMVm chemotaxis and reducing $\mathrm{KC}$-induced neutrophil migration, it is unlikely that the HdE directly bound WKYM$\mathrm{Vm}$, although this possibility has not unequivocally been ruled out.

\section{A Heat-and Trypsin-Sensitive Glycoprotein in the}

HdE Suppressed Neutrophil Migration

Considering the physico-chemical nature of the bioactive molecules(s) within the HdE, boiling, trysinization and sodium-metaperiodate (to disrupt glycans) treatment of the HdE ablated its ability to inhibit WKYMVminduced chemotaxis, whereas acidification did not affect HdE's ability to reduce neutrophil chemotaxis (Fig. 6ad).

Cognizant of low level of LPS contamination in HdE, we speculated that this may contribute to the inhibition of neutrophil chemotaxis. However, the addition of polymyxin B to the HdE did not affect its ability to inhibit murine neutrophil migration, and pre-treatment of neutrophils with HdE and LPS did not enhance further the suppression of chemotaxis in response to WKYMVm (Fig. 6e).

Tapeworm Suppression of Neutrophil Chemotaxis

\section{The Molecular Mechanism}

As reported [21], we also find that WKYMVm-evoked chemotaxis in neutrophils is completely blocked by the selective pharmacological inhibitor of p38 mitogen-activated protein kinase (MAPK), SB20350 (Fig. 7a). The inhibitor of the ERK1/2 MAPK pathway, U0126, blocked neutrophil by $\sim 40 \%$ in the transwell migration assay (data not shown). Focusing on the p38 MAPK pathway, we observed that the activation (i.e., phosphorylation) of p38 MAPK and the downstream signalling molecule, HSP27, by WKYMVm (10 min treatment) was substantially reduced by co-treatment with $\mathrm{HdE}$ (Fig. 7b).

\section{Discussion}

Often overlooked in the context of infection with parasitic helminths, the potential of neutrophils to kill larval nematodes in vitro was observed in 1979 [22]. Since then neutrophils have been shown to participate in the host response to helminths, but it is not always clear if they are mobilized because of concomitant tissue damage [7], the parasite (or its eggs/products) per se $[6,23]$, or bacteria from the helminth as described for Wolbachia endobacteria causing neutrophil accumulation around the filarial nematode, Onchocerca volvulus [24].

Infection with $H$. diminuta suppressed the severity of DNBS-induced colitis and CFA-induced arthritis in mice, one indicator of which was reduced MPO and hence neutrophil infiltration into the tissue $[12,13]$. Whether this was due to reduced chemokine production by the host and/or related to bioactive molecules from the worm was not determined. Here, the injection of LPS into the mouse knee resulted in an accumulation of neutrophils that was significantly reduced by co-treatment with a PBS-soluble extract of $H$. diminuta (HdE). While consistent with the findings in the DNBS and CFA models of inflammation, reduced neutrophil recruitment to the knee of HdE-treated 

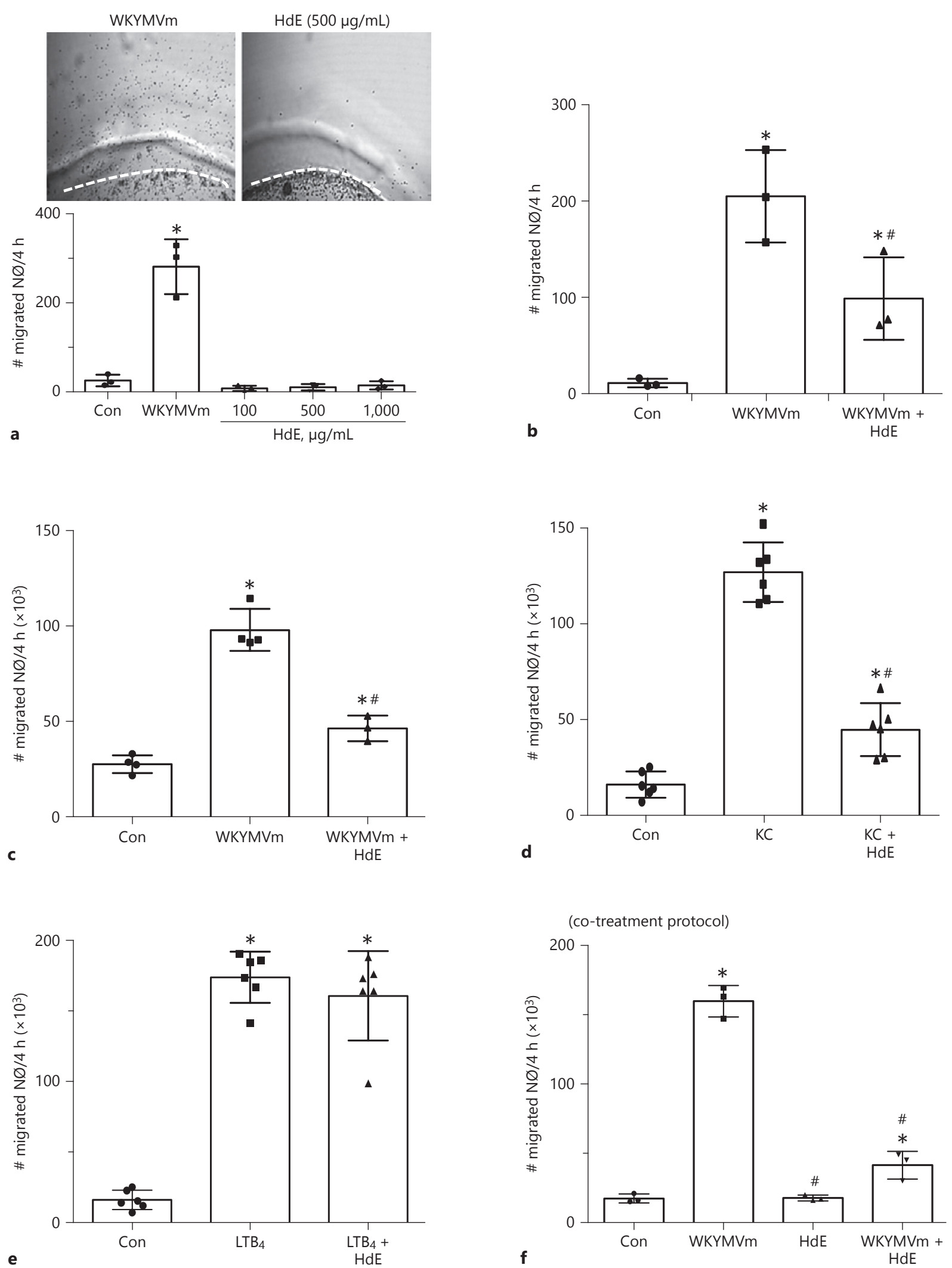

(For legend see next page.) 
Fig. 5. $H$. diminuta extract (HdE) suppression of neurophil chemotaxis is not dependent on reactive oxygen species (ROS). Murine bone marrow neutrophil $\left(2 \times 10^{5}\right.$ $\mathrm{N} \oslash \mathrm{s})$ migration towards WKYMVm $(1 \mu \mathrm{M})$ in a transwell assay $(8 \mu \mathrm{m}$ pore size filter) is unaffected by a $30 \mathrm{~min}$ pre-treatment with LPS $(1 \mu \mathrm{g} / \mathrm{mL})$ or the calcium ionophore, A23187 (2.5 $\mu \mathrm{M})$. Moreover, suppression of $\mathrm{N} \varnothing$ chemotaxis by Hymenolepis diminuta extract ( $\mathrm{HdE}, 100 \mu \mathrm{g} / \mathrm{mL}$ ) was unaffected by co-treating the NØs with the anti-apoptotic pan-caspase inhibitor, Z-VAD $(20 \mu \mathrm{M})$ or the antioxidants, n-acetylcystine (NAC, $1 \mu \mathrm{M}$ ) or mitoTEMPT $(\mathrm{mTEMPO}, 10 \mu \mathrm{M})$ (data are mean $\pm \mathrm{SD}$; each datum point is the average of $2 \mathrm{~N} \varnothing$ replicates from an individual mouse, ${ }^{*}$ and \#, $p<0.05$ compared to control (con) and WKYMVm only, respectively, by one-way analysis of variance with Tukey's posttest).

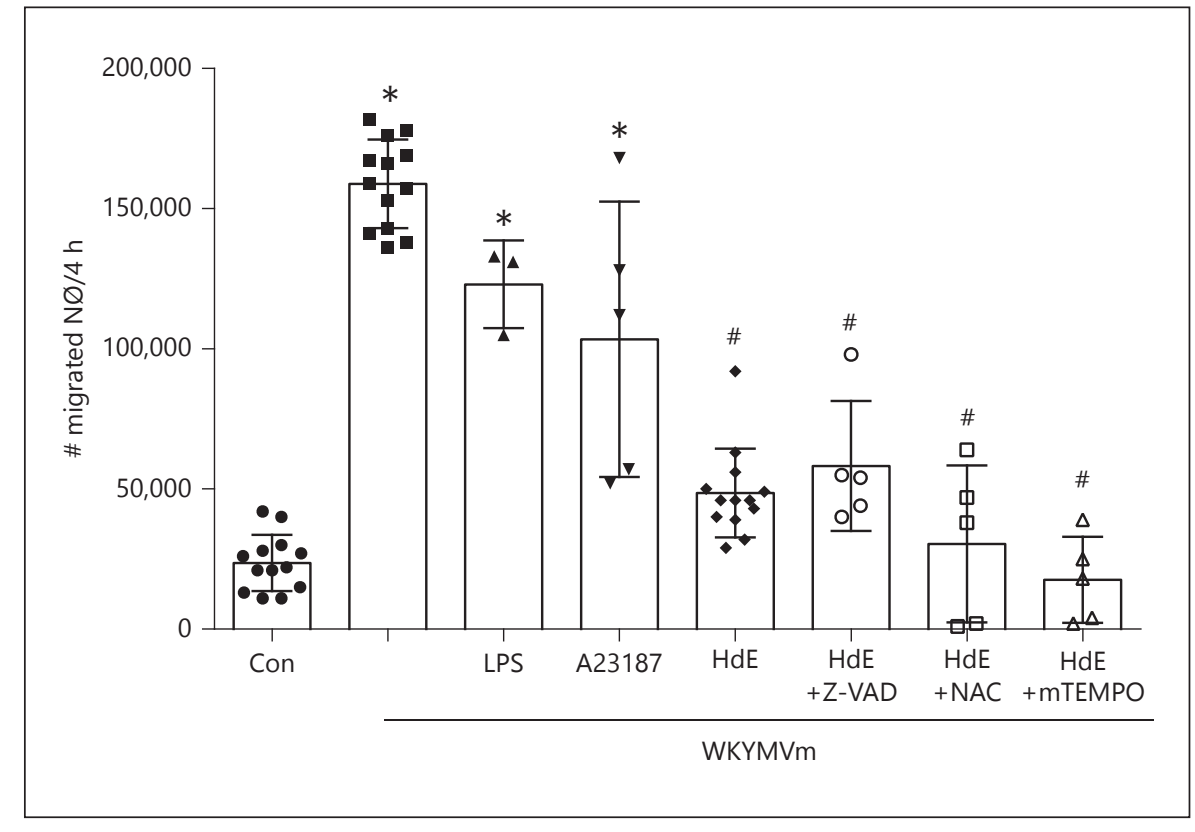

mice does not differentiate between direct and indirect effects of the HdE on the neutrophil. It was possible that the HdE was acting as a distraction, attracting neutrophils into the peritoneal cavity (noting that HdE evoked increases in $\mathrm{KC}$ in the peritoneal cavity), but this is unlikely to be the full explanation, since neither bone marrow nor blood levels of neutrophils were reduced in the HdE-treated mice.

Murine neutrophils were responsive to the $\mathrm{HdE}$ as gauged by $\mathrm{Ca}^{2+}$ mobilization, ROS generation (a component of which would arise from the noted $\mathrm{H}^{+}$leak in mitochondria) and reduced mitochondrial capacity to make ATP, although, and perhaps surprisingly, the HdE did

Fig. 4. H. diminuta extract (HdE) suppresses WKYMVm and KCinduced chemotaxis in murine bone marrow neutrophil. Freshly isolated neutrophils $\left(2 \times 10^{5} \mathrm{~N} \emptyset\right.$ s $)$ were placed in the outside wells of an ultrapure agarose gel and chemotaxis towards HdE or WKYMVm $(1 \mu \mathrm{M})$ assessed (a upper panels are representative images showing extensive migration of neutrophils out of the well (demarcated by the dashed line) in response to WKYMVm but not $\mathrm{HdE})$. b shows that $\mathrm{N} \emptyset$ s pretreated with $\mathrm{HdE}(100 \mu \mathrm{g} / \mathrm{mL}, 30 \mathrm{~min})$ had reduced chemotaxis to WKYMVm. Using a transwell $(8 \mu \mathrm{m}$

Fig. 6. A heat-, trypsin-sensitive glycoprotein mediates the effect of $H$. diminuta extract (HdE) on neutrophil chemotaxis. Murine bone marrow neutrophils $\left(2 \times 10^{5} \mathrm{~N} \varnothing\right.$ s) were treated with (a) boiled (boil), (b) trypsinized (tryp), (c) sodium metaperiodate (SMP) or (d) acidified (acid) HdE $(100 \mu \mathrm{g} / \mathrm{mL})$ and placed in the upper chamber of the transwell $(8 \mu \mathrm{m}$ pore size filter $)$ separated from WKYMVm $(1 \mu \mathrm{M})$ and $N \varnothing$ migration assessed $4 \mathrm{~h}$ later. Pan- not elicit KC, IL-10 or TNF- $\alpha$ production directly from neutrophils. HdE-evoked ROS generation was not affected by use of polymyxin B to absorb LPS, suggesting that the effect was not because of this bacterial contaminant in the HdE. The scientific literature is replete with examples of helminth-derived excretory/secretory products, extracts or semi-purified molecules directly affecting a variety of functions of innate immune cells $[25,26]$. Indeed, products from nematode and trematode parasites can be chemoattractants for neutrophils in vitro [27-29]: thus, it was unexpected when HdE failed to elicit neutrophil chemotaxis in under-agarose or transwell systems. Contrari-

pore size) migration system revealed that $\mathrm{HdE}$ inhibited $\mathrm{N} \varnothing$ chemotaxis to WKYMVm (c) and $\mathrm{KC}(20 \mathrm{ng} / \mathrm{mL}$; d), but not leukot-

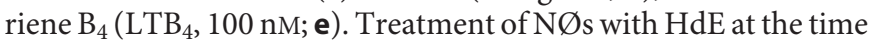
of application of WYKMVm to the culture well (co-treatment) also suppressed chemotaxis (f; data are mean \pm SD; each datum point is the average of $2 \mathrm{~N} \varnothing$ replicates from an individual mouse; ${ }^{*}$ and ${ }^{\#} p<0.05$ compared to control [con] or the appropriate chemotactic stimulus only, respectively, by one-way analysis of variance with Tukey's post-test).

el $\mathrm{D}$ shows the lack of an effect of applying polymyxin $\mathrm{B}(\mathrm{PmxB}$; $10 \mu \mathrm{g} / \mathrm{mL})$ or E. coli-derived LPS (1 ng/mL) on the HdE-suppression of chemotaxis (data are mean $\pm \mathrm{SD}$; each datum point is the average of $2 \mathrm{~N} \varnothing$ replicates from an individual mouse, ${ }^{*}$ and ${ }^{\#} p<$ 0.05 compared to control (con) and WKYMVm only, respectively, by one-way analysis of variance with Tukey's post-test).

(For figure see next page.) 

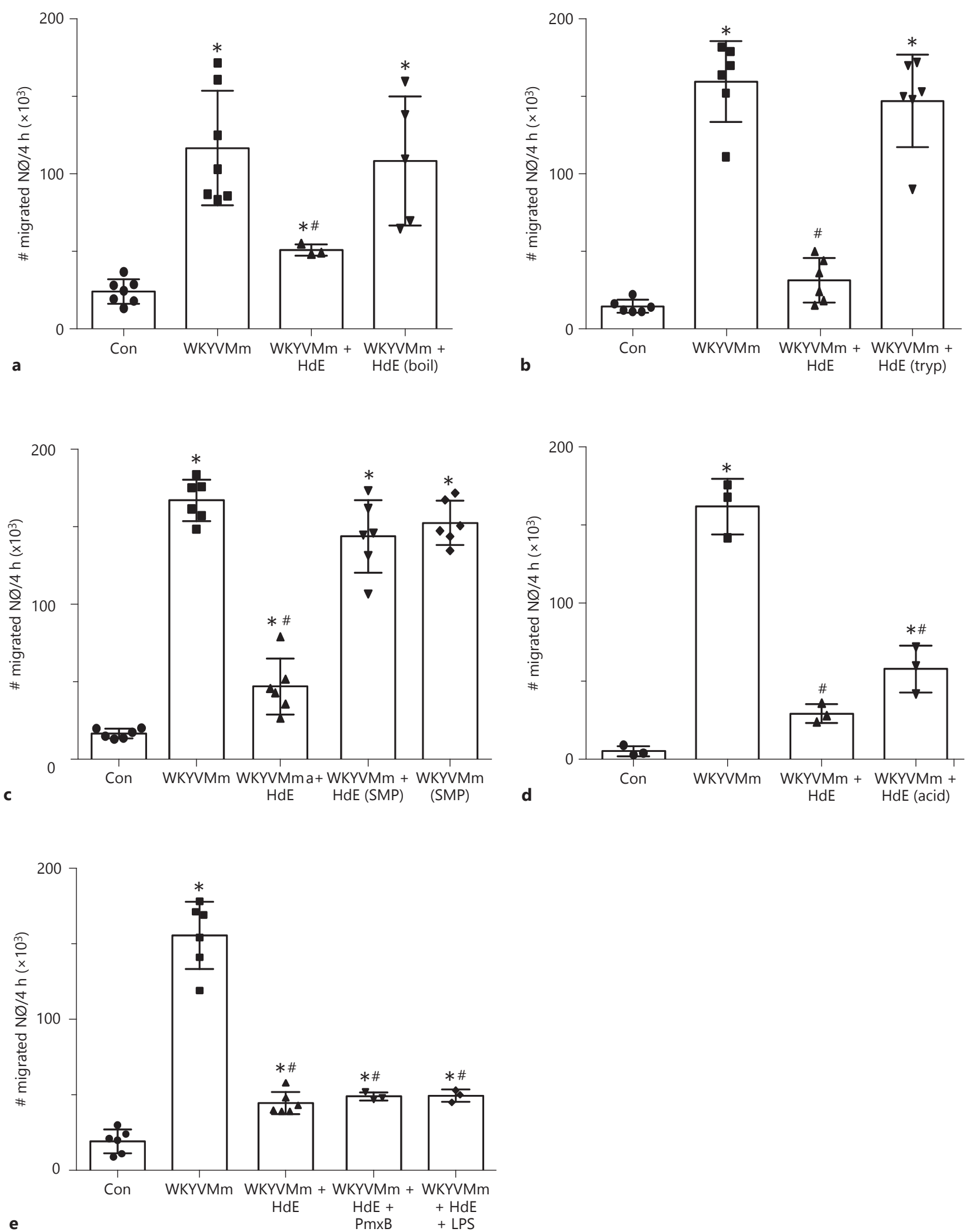
Fig. 7. H. diminuta extract (HdE) suppression of neutrophil chemotaxis occurs via p38 MAP kinase. a Murine bone marrow neutrophil $\left(2 \times 10^{5}, \mathrm{~N} \emptyset \mathrm{s}\right)$ migration in a transwell $(8 \mu \mathrm{m}$ pore size filter $)$ in response to the peptide WKYMVm $(1 \mu \mathrm{M})$ is completely blocked by pre-treatment (30 min, $37^{\circ} \mathrm{C}$ ) with the selective pharmacologic inhibitor of the p38 mitogen-activated protein kinase (MAPK) pathway, SB20350 $(2.5 \mu \mathrm{M})$ (data is mean $\pm \mathrm{SD}$; each datum point is the average of $2 \mathrm{~N} \varnothing$ replicates from an individual mouse; * and ${ }^{\#} p<0.05$ compared to control (con) or WKYMVm only, respectively, by one-way analysis of variance with Tukey's post-test). b Immunoblots show that activation of $\mathrm{p} 38$ in $\mathrm{N} \varnothing \mathrm{s}$ and the downstream signal heat-shock protein (HSP) 27 by WKYMVm is inhibited by the co-treatment with $\mathrm{HdE}(100 \mu \mathrm{g} / \mathrm{mL}$; $10 \mathrm{~min}, 37^{\circ} \mathrm{C}$; representative immunoblot and densitometric analysis where data are mean $\pm \mathrm{SD}, \# p<0.05$ compared to WKYMVm only, by Kruskal-Wallis test with Dunn's post-test).
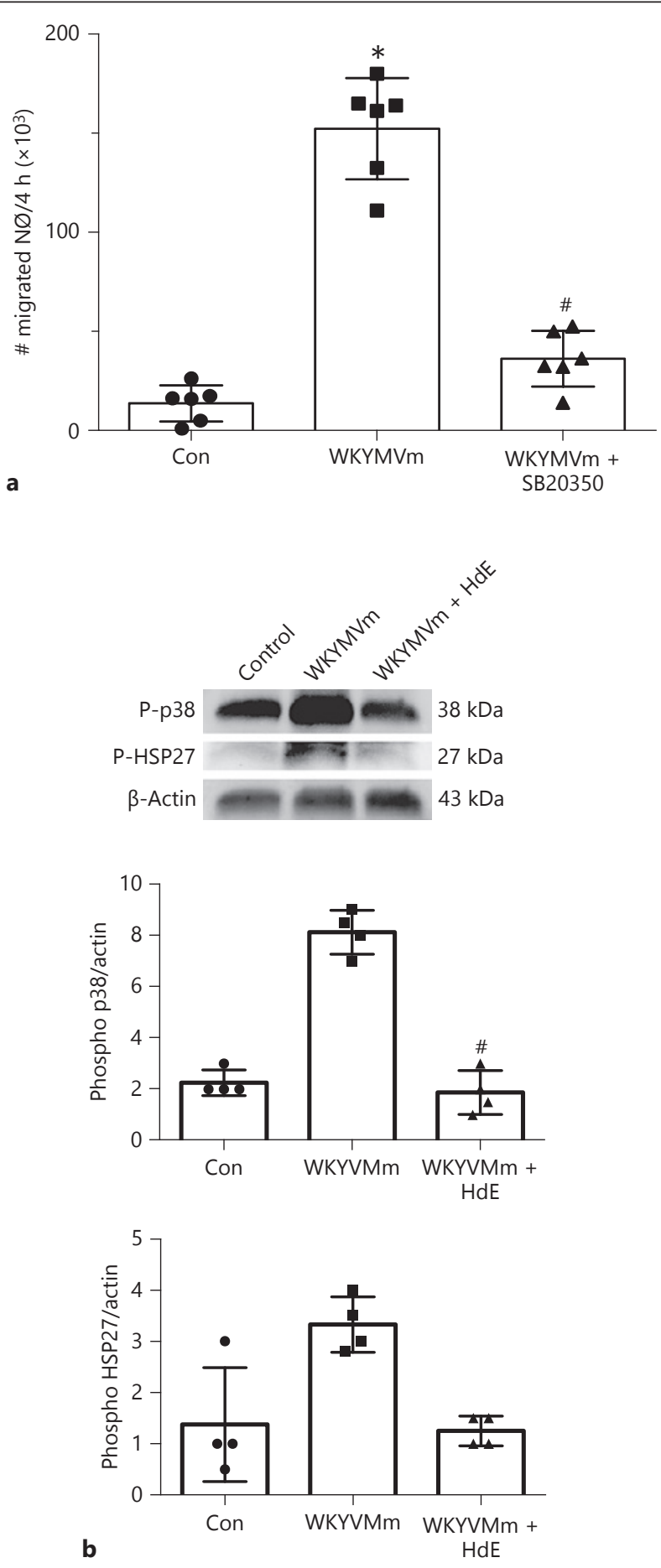

ly, when added to neutrophils as a pre- or co-treatment, HdE significantly suppressed migration towards the chemotactic penta-peptide, WKYMVm. Inhibition of neutrophil chemotaxis by HdE also occurred with the murine chemokine $\mathrm{KC}$, but not the lipid mediator, $\mathrm{LTB}_{4}$. This reveals that the neutrophil retained the ability to rearrange its cytoskeleton and migrate (and that neutrophil viability was not an issue), suggesting that the $\mathrm{HdE}$ effect was restricted to peptide chemoattractants. Moreover, this was not because of neutrophil exhaustion due to the 
HdE-evoked oxidative burst or $\mathrm{Ca}^{2+}$ mobilization, since WKYMVm chemotaxis was unaffected by LPS exposure or treatment with the $\mathrm{Ca}^{2+}$ ionophore, A23187. Mechanistically, ROS neutralization did not affect the HdE suppression of WKYMVm-induced neutrophil migration.

The suppression of neutrophil chemotaxis is intriguing, particularly since other reports on helminth-derived molecules describe them as neutrophil chemoattractants [2730]. Schroeder et al. reported that live microfilariae of Brugia malayi blocked transendothelial migration of neutrophils but did not determine if this was via the release of a molecule from the nematode [31]. We add 2 speculative points when interpreting our data. One, identification of the bioactive molecule(s) within the HdE could yield a blueprint for the development of a new drug to direct neutrophil movements in the treatment of disease. Two, the HdE by acting as a "don't leave" signal could retain neutrophils in a tissue, potentially prolonging their activity and, where following apoptosis, they act as an important second signal to promote the reparative function of AAMs [32].

With few exceptions $[33,34]$, the identification of molecules from parasitic helminths has proved challenging. Characterization of the nature of the HdE revealed that the component that blocked neutrophil chemotaxis was a heat- and trypsin-sensitive glycan (SMP-sensitive), most likely a proteoglycan that was resistant to acidification. Similarly, a $H$. diminuta glycan was found to suppress LPS-evoked TNF- $\alpha$ production from macrophages [14], and numerous findings support the ubiquity of helminth-derived glycans in the modulation of host immunity $[25,35]$. So while the challenge remains to identify the structure of the anti-chemotactic molecule(s) from $H$. diminuta, the search has been narrowed to a heat- and trypsin-sensitive proteoglycan.

Cell chemotaxis is a coordinated process [36], in which the p38 MAPK directs neutrophil migration in response to KC/IL-8 and formyl-peptide receptor ligands such as WKYMVm [37], but not $\mathrm{LTB}_{4}$ [38]: the leukotriene may be an important synergist stimulus of neutrophil chemotaxis [39] and has been shown to amplify eosinophil accumulation in response to infection with nematodes [40]. Following confirmation that pharmacological blockade of p38 MAPK signalling prevented WKYMVm-induced neutrophil chemotaxis, immunoblotting revealed that HdE-treated neutrophils displayed diminished activation of p38 MAPK and the downstream signal, HSP27 (important in chemotaxis [36]), in response to the challenge with WKYMVm. Subsequent research efforts need to be directed towards more fully elucidating HdE's mechanism of action that could involve binding with and blocking the
FPR and KC receptors, or HdE mobilizing a signalling cascade that inhibits p38 MAPK phosphorylation directly or targets up-stream molecules such as phosphatidylinositol 3'-kinase [38].

What of the paradox of HdE injection resulting in accumulation of neutrophils in the peritoneum of mice compared to the suppression of chemotaxis in vitro. This most likely reflects the target cells of the HdE. With direct access to the neutrophil (in vitro analyses), the HdE will suppress neutrophil chemotaxis to WKYMVm or KC. However, in vivo HdE can evoke the production of neutrophil chemoattractants (KC was increased in the peritoneum) by other cells, possibly myeloid cells, which would attract neutrophils that have not been affected by direct contact with the HdE.

Often considered a pariah because of its capacity for collateral tissue damage upon activation, the neutrophil, alive or dead, is an important player in host immunity [1]: alive it performs critical anti-microbial functions, while apoptotic neutrophils may be important in promoting a tissuehealing phenotype in murine AAMs [32]. Here we show that a PBS-soluble extract of the cestode $H$. diminuta activates murine neutrophils and that a trypsin-sensitive proteoglycan in the extract blocks WKYMVm- and KC-induced chemotaxis via suppression of 38 MAPK signalling. While the exact nature of the bioactive molecule(s) of the helminth-derived molecules awaits determination, and the full significance of these changes in neutrophil function for host immunity needs to be defined, the current study reinforces the folly of overlooking the role that neutrophils play in the host response to infection with parasitic helminths.

\section{Acknowledgements}

Funding provided by a Natural Science and Engineering Research Council of Canada (NSERC) grant to Derek M. McKay. Nicholas Graves was supported by a Graduate Studentship from the NSERC CREATE Host-Parasite Interactions Program at University Calgary. Fernando Lopes was supported by Canadian Institutes of Health Research (CIHR)/Canadian Association of Gastroenterology (CAG)/Allergan Inc. and Alberta Innovates-Health solutions (AI-HS) Post-Doctoral Fellowships. Derek M. McKay holds a Canada Research Chair (CRC: Tier 1) in Intestinal Immunophysiology in Health and Disease. We thank Dr. M. Hollenberg and M. Saifeddine (University Calgary) for access to and assistance with the calcium measurement assay.

\section{Disclosure Statement}

The authors declare that they have no disclosures to disclose. 


\section{References}

1 Kubes P: The enigmatic neutrophil: what we do not know. Cell Tiss Res 2018;371:399-406.

2 Pionnier N, Brotin E, Karadjian G, et al: Neutropenic mice provide insight into the role of skin-infiltrating neutrophils in the host protective immunity against filarial infective larvae. PLoS Negl Trop Dis 2016;10:e0004605.

3 Munoz-Caro T, Rubio RM, Silva LM, et al: Leucocyte-derived extracellular trap formation significantly contributes to Haemonchus contortus larval entrapment. Parasit Vectors 2015;8:607.

4 O'Connell AE, Hess JA, Santiago GA, et al: Major basic protein from eosinophils and myeloperoxidase from neutrophils are required for protective immunity to Strongyloides stercoralis in mice. Infect Immunity 2011;79: 2770-2778.

5 Vatta AF, Dzimianski M, Storey BE, et al: Ivermectin-dependent attachment of neutrophils and peripheral blood mononuclear cells to Dirofilaria immitis microfilariae in vitro. Vet Parasitol 2014;206:38-42.

6 Gazzinelli-Guimaraes PH, Gazzinelli-Guimaraes AC, Silva FN, et al: Parasitological and immunological aspects of early Ascaris spp. infection in mice. Internat J Parasitol 2013;43: 697-706.

7 Chen F, Wu W, Millman A, et al: Neutrophils prime a long-lived effector macrophage phenotype that mediates accelerated helminth expulsion. Nat Immunol 2014;15:938-946.

8 Bonne-Annee S, Kerepesi LA, Hess JA, et al: Human and mouse macrophages collaborate with neutrophils to kill larval Strongyloides stercoralis. Infect Immunity 2013;81:33463355.

9 Sutherland TE, Logan N, Ruckerl D, et al: Chitinase-like proteins promote IL-17-mediated neutrophilia in a tradeoff between nematode killing and host damage. Nat Immunol 2014; 15:1116-1125.

10 Lopes F, Matisz C, Reyes JL, et al: Helminth regulation of immunity: a three-pronged approach to treat colitis. Inflamm Bowel Dis 2016;22:2499-2512.

11 Navarro S, Pickering DA, Ferreira IB, et al: Hookworm recombinant protein promotes regulatory $\mathrm{T}$ cell responses that suppress experimental asthma. Sci Translat Med 2016;8: 362 ra143.

12 Hunter MM, Wang A, Hirota CL, McKay DM: Neutralizing anti-IL-10 antibody blocks the protective effect of tapeworm infection in a murine model of chemically induced colitis. J Immunol 2005;174:7368-7375.

13 Shi M, Wang A, Prescott D, et al: Infection with an intestinal helminth parasite reduces Freund's complete adjuvant-induced monoarthritis in mice. Arthritis Rheum 2011;63: 434-444.
14 Johnston MJ, Wang A, Catarino ME, et al: Extracts of the rat tapeworm, Hymenolepis diminuta, suppress macrophage activation in vitro and alleviate chemically-induced colitis in mice. Infect Immunity 2010;78:1364-1375.

15 Lopes F, Coelho FM, Costa VV, et al: Resolution of neutrophilic inflammation by $\mathrm{H}_{2} \mathrm{O}_{2}$ in antigen-induced arthritis. Arthritis Rheum 2011;63:2651-2660.

16 Swamydas M, Luo Y, Dorf ME, Lionakis MS: Isolation of mouse neutrophils. Curr Protocol Immunol 2015;110:3.20.1-3.20.15.

17 Dranka BP, Benavides GA, Diers AR, et al: Assessing bioenergetic function in response to oxidative stress by metabolic profiling. Free Rad Biol Med 2011;51:1621-1635.

18 Yang L, Na CL, Luo S, et al: The phosphatidylcholine transfer protein stard7 is required for mitochondrial and epithelial cell homeostasis. Scient Rep 2017;7:46416.

19 Heit B, Kubes P: Measuring chemotaxis and chemokinesis: the under-agarose cell migration assay. Sci STKE 2003;2003:PL5.

20 Lopes F, Graepel R, Reyes JL, et al: Involvement of mast cells in $a 7$ nicotinic receptor agonist exacerbation of Freund's complete adjuvant-induced monoarthritis in mice. Arthritis Rheum 2016;68:542-552.

21 de Oliveira S, Rosowski EE, Huttenlocher A Neutrophil migration in infection and wound repair: going forward in reverse. Nat Rev Immunol 2016;16:378-391.

22 Bass DA, Szejda P: Mechanisms of killing of newborn larvae of Trichinella spiralis by neutrophils and eosinophils. Killing by generators of hydrogen peroxide in vitro. J Clin Invest 1979;64:1558-1564.

23 Chuah C, Jones MK, Burke ML, McManus DP, Owen HC, Gobert GN: Defining a proinflammatory neutrophil phenotype in response to schistosome eggs. Cell Microbiol 2014;16:1666-1677.

24 Tamarozzi F, Wright HL, Johnston KL, Edwards SW, Turner JD, Taylor MJ: Human filarial Wolbachia lipopeptide directly activates human neutrophils in vitro. Parasite Immunol 2014;36:494-502.

25 Johnston MJ, MacDonald JA, McKay DM: Parasitic helminths: a pharmacopeia of antiinflammatory molecules. Parasitology 2009; 136:125-147.

26 Harnett W: Secretory products of helminth parasites as immunomodulators. Mol Biochem Parasitol 2014;195:130-136.

27 Jefferies JR, Corbett E, Barrett J, Turner RJ: Polarization and chemokinesis of ovine and human neutrophils in response to Fasciola hepatica excretory-secretory products. Internat J Parasitol 1996;26:409-414.

28 Reinhardt S, Scott I, Simpson HV: Neutrophil and eosinophil chemotactic factors in the ex- cretory/secretory products of sheep abomasal nematode parasites: NCF and ECF in abomasal nematodes. Parasitol Res 2011;109:627635.

29 Wu C, Chen Q, Fang Y, et al: Schistosoma japonicum egg specific protein $\mathrm{SjE} 16.7$ recruits neutrophils and induces inflammatory hepatic granuloma initiation. PLoS Negl Trop Dis 2014;8:e2703.

30 O'Connell AE, Redding KM, Hess JA, Lok JB, Nolan TJ, Abraham D: Soluble extract from the nematode Strongyloides stercoralis induces CXCR2 dependent/IL-17 independent neutrophil recruitment. Microbes Infect 2011;13:536-544.

31 Schroeder JH, Simbi BH, Ford L, et al: Live Brugia malayi microfilariae inhibit transendothelial migration of neutrophils and monocytes. PLoS Negl Trop Dis 2012;6:e1914.

32 Bosurgi L, Cao YG, Cabeza-Cabrerizo M, et al: Macrophage function in tissue repair and remodeling requires IL-4 or IL-13 with apoptotic cells. Science 2017;356:1072-1076.

33 Ahmed UK, Maller NC, Iqbal AJ, Al-Riyami L, Harnett W, Raynes JG: The carbohydratelinked phosphorylcholine of the parasitic nematode product ES-62 modulates complement activation. J Biol Chem 2016;291: 11939-11953.

34 Everts B, Hussaarts L, Driessen NN, et al: Schistosome-derived omega-1 drives Th2 polarization by suppressing protein synthesis following internalization by the mannose receptor. J Exp Med 2012;209:1753-1767.

35 Velupillai P, Harn DA: Oligosaccharide-specific induction of interleukin 10 production by $\mathrm{B}_{2} 20^{+}$cells from schistosome-infected mice: a mechanism for regulation of $\mathrm{CD} 4^{+} \mathrm{T}$ cell subsets. Proc Nat Acad Sci U S A 1994;91: 18-22.

36 Cuenda A, Rousseau S: p38 MAP-kinases pathway regulation, function and role in human diseases. Biochim Biophys Acta 2007; 1773:1358-1375.

37 Cara DC, Kaur J, Forster M, McCafferty DM, Kubes P: Role of p38 mitogen-activated protein kinase in chemokine-induced emigration and chemotaxis in vivo. J Immunol 2001;167: 6552-6558.

38 Heit B, Tavener S, Raharjo E, Kubes P: An intracellular signaling hierarchy determines direction of migration in opposing chemotactic gradients. J Cell Biol 2002;159:91-102.

39 Lammermann T, Afonso PV, Angermann BR, et al: Neutrophil swarms require $\mathrm{LTB}_{4}$ and integrins at sites of cell death in vivo. $\mathrm{Na}$ ture 2013;498:371-375.

40 Patnode ML, Bando JK, Krummel MF, Locksley RM, Rosen SD: Leukotriene $\mathrm{B}_{4}$ amplifies eosinophil accumulation in response to nematodes. J Exp Med 2014;211:1281-1288. 